Island, New York, NY: 239 pp.

JOHNSON, Brian (1978), Banking on the Biosphere. Development Forum, 6(7), pp. 1-8.

KNAMILLER, Gary W. (1979a). Environmental education and the Third World. The Journal of Environmental Education, 10(4), pp. 7-11.

KNAMILLER, Gary W. (1979b). School-based environmental monitoring in developing countries. Science Teacher, 23 (1 \& 2), pp. 41-5 and 48-62.
KNAMILLER, Gary W. \& OBENG-ASAMOAH, John (1979). The child in the community_Ghanaian children's perceptions. The Journal of Environmental Education, 10(4), pp. $21-7$.

MISHAN, E. J. (1967). The Costs of Economic Growth. Pelican, London, England, UK: $240 \mathrm{pp}$.

UNESCO (1976). Final Report. Conference of Ministers of Education of African Member States, Lagos, 27 January-2 February 1976. UNESCO, Paris, France: $62 \mathrm{pp}$.

\title{
Preparing for the Worst in the Caribbean
}

The Caribbean has repeatedly been victimized by hurricanes, earthquakes, and volcanoes, at a cost often of millions of dollars of damage and thousands of human lives. An average of eight hurricanes and tropical storms pass through the region each year; earthquakes have devastated nearly every major city at least once in the last 300 years; and out of the 17 volcanoes in the Lesser Antilles alone, nine have erupted in recorded history.

While the situation of people living in the region is extremely insecure, efforts to change it are now being made. Last April in Montego Bay, Jamaica, an intergovernmental conference was organized by the United Nations Environment Programme (UNEP) and the United Nations Economic Commission for Latin America (ECLA), at which 24 of the 27 Caribbean governments adopted an action plan which includes provisions for (1) determining the nature and magnitude of the risk from natural disasters in the Caribbean, (2) assessing the potential impact of earthquakes on the region's economy, (3) evaluating the status of disaster preparedness throughout the region, and (4) strengthening cooperative links among Caribbean countries relating to disaster relief, prevention, and environmental recovery.

'Disaster prevention' is defined as those measures which are designed to prevent natural phenomena from causing or resulting in disaster or related emergency situations, and 'disaster preparedness' as action taken to minimize human and economic losses and to facilitate effective rescue, relief, and rehabilitation, through up-todate national plans.

The disaster prevention and preparedness measures included in the Caribbean Action Plan reflect the recommendations of a Disaster Preparedness Seminar held in St Lucia in June 1979, under the sponsorship of 11 international organizations. The seminar was attended by over 150 scientists, technical experts, and government representatives, who exchanged their experiences, discussed ways to cooperate with one another, and examined the 'state of the art' of early warning of natural disasters.

To convey some idea of the magnitude of these natural disasters: when hurricane 'Fifi' struck the Caribbean in 1974 , between 8,000 and 10,000 people died. In 1979, hurricanes 'David' and 'Frederick' killed over 2,000 in the Dominican Republic and caused nearly a thousand million dollars' worth of damage. In 1980, when hurricane 'Allen' spent most of its force over Haiti, St Lucia, and Jamaica, the total damages were estimated at 630 million dollars. In Jamaica in 1692, in Caracas in 1812 , and in Guadeloupe in 1843, earthquakes levelled buildings and killed a third of the local populations. In 1976 an earthquake in Guatemala left nearly 23,000 dead and did over a thousand million dollars' worth of damage. Parts of the Caribbean tectonic belt have been ominously quiet in recent decades; subterranean defor- mation in these areas could be building up towards a major seismic rupture.

At St Pierre, Martinique, in 1902, an eruption of Mount Pelée unleashed enough kinetic energy to demolish massive buildings, strip the superstructure from ships in the harbour, and launch debris which impaled and dismembered many of the 28,000 people who died. An eruption of La Soufrière on the island of St Vincent in 1979 shot steam and dust 19,000 metres into the air, damaging crops and livestock, and forcing about 20,000 people into evacuation centres for two months.

\section{Effects of Hurricanes}

Hurricanes in the Caribbean, typhoons in the Pacific, and cyclones in the Bay of Bengal, are storms characterized by rotating winds which reach speeds in excess of $118 \mathrm{kph}$. They vary in size, force, and endurance, and are exceedingly difficult to track, as they can change direction suddenly and unpredictably. Most hurricane damage is done by storm-surge, and most lives are lost by drowning. At greatest risk are people living in lowlying coastal areas and adjacent plains. This danger-zone includes all of the Caribbean island capital cities.

Winds associated with hurricanes and tropical storms also cause great damage, both directly and indirectly, through flying debris, uprooted trees, and fallen powerlines. Heavy rain can cause serious flooding. Tornadoes often lead the way, arriving 6 to 12 hours before the hurricane itself.

The severity of a hurricane's effects is largely determined by the condition of the land that it hits-its contours, its covering vegetation, and the use to which it has been put. Destruction of the natural vegetation clears the way for floods and landslides, fills rivers with eroded sediment, and leaves human settlements unprotected. A case in point is Cuba, where far more damage from storm-winds has occurred in deforested areas than where forest cover remained intact. In a similar manner, coral reefs, sand-dunes, and coastal mangrove forests, play a large role in reducing wave-action from hurricanes and submarine volcanoes. Consequently their destruction can be very expensive-in terms of loss of life and damage to coastlines - as can be the cost of erecting seawalls and jetties to replace natural barriers.

Severe secondary effects of hurricanes include damage to agriculture, which can lead to famine and to economic disaster for small islands that are dependent on one or two export crops. In 1963, tropical storm 'Helena' destroyed $50 \%$ of the sugar-cane and $95 \%$ of the banana crop in Guadeloupe. Recovery can be delayed when soil is degraded by erosion or inundation with salt water.

Reducing the effects of hurricanes can be carried out in a number of ways: improvement of weather forecasting, tracking systems, and communications, so that storm 
warnings are given in time, is the most obvious of these. But equally important are the long-term measures incorporated into urban planning.

Land-use zoning can restrict industrial and residential development in high-risks areas. Building codes can ensure minimum safety-standards in areas exposed to stormsurge and high winds. Conservation of soil and of marine and terrestrial ecosystems can guard against erosion and wave action, and preserve the natural buffers which have protected the islands and mainland coasts for millennia. The Caribbean Action Plan calls for these measures, as well as for an extensive programme of risk analysis of meteorological phenomena.

\section{Earthquakes and Volcanoes}

Perhaps the most disturbing problem with regard to earthquakes is the ever-increasing vulnerability of the human population. This is largely due to the fact that most new buildings are constructed of unreinforced masonry rather than wood-making them relatively resistant to hurricanes, but extremely vulnerable to earthquakes. Also, enormous investments have been made in industrial development, dams, pipelines, power-transmission facilities, and harbours-all easily damaged by earth tremors. An earthquake that could be expected to kill about $5 \%$ of the population and destroy $5 \%$ of the gross national product of a country 50 years ago could now destroy $50 \%$ in the same region. What was once a relatively minor hazard is consequently now a very major one.

Volcanoes threaten only about $1.3 \%$ of the population of the Caribbean, but their effects can be proportionally more lethal. External burns, internal burns of the mouth, and asphyxiation from breathing steam mixed with hot dust, are the usual causes of death from hot avalanches, which are considered the most dangerous feature of West Indian eruptions. Large vertical explosions, called volcanic eruptions, shower areas downwind with pebbles and ash. Mud-flows are a special hazard if volcanoes have large crater-lakes, and secondary mud. flows can occur for years after an eruption during heavy rains. Tsunami, or giant sea-waves, can be produced by submarine eruptions.

Earthquakes and volcanic eruptions are considerably harder to predict than hurricanes, but improvements in prediction techniques are being made. St Vincent, in response to its 1979 eruption, is building a volcano observatory and establishing a permanent network of seismic stations around the volcano. Guadeloupe and Martinique already have similar monitoring systems. The Caribbean Action Plan foresees establishment of a volcanic emergencies task-force, which will identify the potentially dangerous volcanoes in the region, create a pool of portable monitoring equipment, and form a panel of regional specialists in emergency relief operations.

Earthquake prediction is still relatively unreliable, however, and it is thought that the adoption, enforcement, and monitoring, of building codes is the most effective means of reducing human and economic losses from earthquakes. Although several such codes exist in draft form, few nations of the Caribbean have building codes with any legal status. One of the action-plan projects is to produce a manual of design and production methods for disaster-resistant housing which should be a valuable guide in developing such codes.

\section{Public Health}

In the aftermath of a natural disaster, public health often becomes a major concern, and any effective disasterprevention plan must make adequate provision for the supply of drinking-water, shelter, and sanitation facilities, on short notice. Famine and epidemics may occur, and on-the-spot surveillance teams should screen disaster victims for signs of malnutrition and disease during the recovery period. The Action Plan encourages regional cooperation in public health measures as a major means of mitigating the damaging effects of disasters.

The countries of the Caribbean are thus busily preparing for the worst - the only way to prevent the worst from happening. Storms will come, earthquakes will shake cities, and once in a while a volcano will erupt. But these events need not be the large-scale disasters that they often are. The Caribbean governments are learning and teaching one another how to keep the effects to a minimum.

\section{Convention on the Conservation of European Wildlife and Natural Habitats}

The Interim Committee for cooperation in the context of what is commonly called the 'Berne Convention', having met from 18 to 20 March 1981 , made several recommendations to the Committee of Ministers of the Council of Europe, asking that the attention of national authorities be drawn to the hazards threatening some species in Europe, such as the Brown Bear (Ursus arctos), the Black Grouse (Lyrurus tetrix), and the plant Artemisia laciniata. Also, a warning was issued to stop some international activities from overlapping.

The establishment of a new network of reserves in the Mediterranean region, as suggested at the Cannes Conference (March 1981), was considered and it was concluded that effective conservation would be more advanced through the encouragement of coordination between the present systems than by adding more. The Committee took a keen interest in a proposal for a resolution on cooperation between the European Community and the Council of Europe, tabled by $\mathrm{Mr}$ H. Muntingh in the European Parliament. The resolution suggested practical measures to be taken against the overlapping of current activities in the environmental protection sector of both bodies, and called for fuller cooperation between them.

European Information Centre for Nature Conservation Council of Europe

B.P. 431 R6 67006 Strasbourg

France. 